\title{
A Study to Assess the Prevalence and Contributing Factors of Abnormal Uterine Bleeding among Women Admitted in MGMCRI from January to December 2019
}

\author{
Iniyaval $\mathrm{R}^{1}$, Jayanthi $\mathrm{B}^{2}$, Lavanya $\mathrm{S}^{3}$, Renuka $\mathrm{K}^{4}$
}

\begin{abstract}
Introduction: About $30 \%$ of women may have unexplained uterine bleeding at some stage in their lives. There are considerable costs to both the economy and the health sector, in addition to the direct effects on the woman and her family. After excessive bleeding has been established, the acronym PALM-COEIN is increasingly being used to classify the causes.

Objectives: To assess the prevalence and to find out the contributing factors of abnormal uterine bleeding (AUB).

Materials and methods: A retrospective study approach was adopted with a descriptive research design. The population for the study includes women diagnosed with AUB. The tool contains demographic variables of women with AUB, clinical variables, and contributing factors to assess AUB by using PALM-COEIN classification.

Results: With regard to age, the maximum 213 (78\%) were in a group of 40 years and above. In the menstrual cycle, 159 (58.2\%) were having a regular cycle. Out of 273 women, 202 (74\%) have no previous history of medical illness. The value of body mass index (BMI) shows 151 (55.3\%) had normal BMI. The prevalence rate was 6.94\%. About 93 (34.1\%) had maximum contributing factor with adenomyosis. Then, 50 (18.3\%) had iatrogenic as a contributing factor. There is no malignancy and hyperplasia and coagulopathy as a contributing factor. According to the findings of this report, AUB can cause unnecessary disruption in women's daily activities, as well as serious medical consequences or exacerbation of anemia. Keywords: Abnormal uterine bleeding, Contributing factors, Prevalence.

Pondicherry Journal of Nursing (2021): 10.5005/jp-journals-10084-12173
\end{abstract}

\section{INTRODUCTION}

Abnormal uterine bleeding (AUB) is a natural event that may result in severe morbidity. ${ }^{1}$ Irregular uterine bleeding is the most common symptom of gynecological conditions, and it is characterized as any form of bleeding that is unusual for an individual patient in terms of duration, frequency, or volume. ${ }^{2} A U B$, like acute and chronic $A U B$, is thought to be a symptom of uterine disease. ${ }^{3} A U B$ and its subgroup, heavy menstrual bleeding (HMB), are common disorders that affect $14-25 \%$ of reproductive-age women and can have a major effect on their physical, social, mental, and material well-being. ${ }^{4}$ About $30 \%$ of women may have unexplained uterine bleeding at some stage in their lives. ${ }^{5}$ There are considerable costs to both the economy and the health sector, in addition to the direct effects on the woman and her family.

After excessive bleeding has been established, the acronym PALM-COEIN is increasingly being used to classify causes: polyp, adenomyosis, leiomyoma, malignancy (and hyperplasia), coagulopathy, ovulatory disorders, endometrial, iatrogenic, and not otherwise classified. The "PALM" are assessed visually (imaging and histopathology) and the "COEIN" are non-structural. ${ }^{5}$ This study examines the prevalence and the contributing factors of AUB using PALM-COEIN classification.

\section{Objectives}

- To assess the prevalence of AUB.

- To find out the contributing factors of AUB.
${ }^{1-3}$ Department of Obstetrics and Gynecology Nursing, Kasturba Gandhi Nursing College, Sri Balaji Vidyapeeth, Puducherry, India

${ }^{4}$ Department of Medical Surgical Nursing, Kasturba Gandhi Nursing College, Sri Balaji Vidyapeeth, Puducherry, India

Corresponding Author: Lavanya S, Department of Obstetrics and Gynecology Nursing, Kasturba Gandhi Nursing College, Sri Balaji Vidyapeeth, Puducherry, India, Phone: +91 9994747440, e-mail: lavanyas@kgnc.ac.in

How to cite this article: Iniyaval R, Jayanthi B, Lavanya S, et al. A Study to Assess the Prevalence and Contributing Factors of Abnormal Uterine Bleeding among Women Admitted in MGMCRI from January to December 2019. Pon J Nurs 2021;14(1):8-10.

Source of support: Nil

Conflict of interest: None

\section{Materials and Methods}

A retrospective study approach was adopted with a descriptive research design. The study was conducted in an obstetrical unit (150 beds) MGMCRI at Puducherry. The population for the study includes women diagnosed with AUB and who got admitted in MGMCRI from January to December 2019. Samples are all the women who were diagnosed with AUB and those who fulfill the inclusion criteria and got admitted to MGMCRI from January to December 2019. The sampling technique used was the cluster sampling technique.

\footnotetext{
(c) The Author(s). 2021 Open Access This article is distributed under the terms of the Creative Commons Attribution 4.0 International License (https:// creativecommons.org/licenses/by-nc/4.0/), which permits unrestricted use, distribution, and non-commercial reproduction in any medium, provided you give appropriate credit to the original author(s) and the source, provide a link to the Creative Commons license, and indicate if changes were made. The Creative Commons Public Domain Dedication waiver (http://creativecommons.org/publicdomain/zero/1.0/) applies to the data made available in this article, unless otherwise stated.
} 


\section{Criteria for Sample Selection} Inclusion Criteria

- Women who were diagnosed with AUB.

- Patients who were diagnosed with AUB and other associated complications.

\section{Exclusion Criteria}

- Women who are having normal menstrual bleeding.

- Pregnant women.

\section{Description of the ToOL}

The tool contains demographic variables of women with AUB, clinical variables, and contributing factors for assessing AUB.

\section{The Tool Consists of Three Parts}

Part I-It consists of demographic variables such as age, education, religion, area of residence, diet pattern, work status, income, type of work, age at menarche, regularity of menses, changing of sanitary pads per day, last child birth (LCB), number of parity, and previous history of medical illness.

Part II-It includes the assessment of clinical variables such as height, weight, body mass index (BMI), and hemoglobin level.

Part-III-It consists of contributing factors of AUB by PALM-COEIN classification.

\section{Procedure for Data Collection}

The data were collected from the available patient case sheets at the period of data collection. After getting proper approval, the data were collected from the patient case sheets based on the demographic and clinical variables that were listed out in the study.

\section{Results}

Frequency and Percentage Distribution of Demographic Variables of Women with Abnormal Uterine Bleeding

With regard to age, the maximum 213 (78\%) were in a group of 40 years and above. In religion, 184 (67.4\%) were Hindu, 45 (16.5\%) were Christians, and 44 (16.1\%) were Muslims. In the area of residence, $154(56.4 \%)$ were residing in rural areas. In the type of diet, 230 (84.2\%) were non-vegetarian. In occupation, 141 (51.6\%) in the group of homemakers. With regard to work, 201 (73.6\%) were doing the sedentary type of work. Age at menarche was 257 (94.1\%) were between 11 and 15 years. In the menstrual cycle, 159 (58.2\%) were having a regular cycle. In changing of sanitary pads per day maximum of $134(49.1 \%)$ had normal (3-5 pads) and 101 (37\%) had heavy (6-10 pads). About 137 (50.2\%) were had their last child birth between 5 years and 20 years. In parity, the highest 247 (90.5\%) were in the multipara group. Out of 273 women, 202 (74\%) have no previous history of medical illness.

\section{Frequency and Percentage Distribution of Clinical Variables of Women with Abnormal Uterine Bleeding}

With regard to a height maximum of 83 (30.4\%) were $150-155 \mathrm{~cm}$. In weight out of 273 samples, 143 (52.4\%) were 50-60 kg. With regard to $\mathrm{BMI}$, the maximum 151 (55.3\%) were had normal BMI. With regard to hemoglobin, the highest 97 (35.6\%) were under the mild anemic group.

\section{Frequency and Percentage Distribution of Total Number of Women with Abnormal Uterine Bleeding from January to December 2019}

\begin{tabular}{llll}
\hline & $\begin{array}{l}\text { Total number of } \\
\text { women admitted in } \\
\text { obstetrics unit MGM- } \\
\text { CRI from January to }\end{array}$ & $\begin{array}{l}\text { Total number of } \\
\text { women with abnor- }\end{array}$ & \\
mal uterine bleeding & \\
from January to & Prevalence rate \\
S. no. & December 2019 & December 2019 & (\%) \\
\hline 1 & 3931 & 273 & 6.94 \\
\hline
\end{tabular}

\section{Frequency and Percentage Distribution of Contributing Factors of Women with Abnormal Uterine Bleeding $n=273$}

\begin{tabular}{llcc}
\hline S. no. & Contributing factors & Frequency & Percentage \\
\hline 1 & P: Polyp & 9 & 3.3 \\
1a & P: Polyp+ L: Leiomyoma & 13 & 4.8 \\
2 & A: Adenomyosis & 93 & 34.1 \\
2a & A: Adenomyosis+ L: Leio- & 10 & 3.7 \\
& myoma & & \\
3 & L: Leiomyoma & 53 & 19.4 \\
4 & M: Malignancy and hyperplasia & 0 & 0 \\
5 & C: Coagulopathy & 0 & 0 \\
6 & O: Ovulatory dysfunction & 4 & 1.5 \\
7 & E: Endometrial disorders & 16 & 5.9 \\
8 & I: latrogenic & 50 & 18.3 \\
9 & N: Not otherwise classified & 25 & 9.2 \\
\hline
\end{tabular}

\section{Discussion}

The first objective of the present study was to assess the prevalence of AUB:

- The prevalence of AUB among women admitted in an obstetrics unit in MGMCRI from January to December 2019, there was a total of 3931 cases out of these this 273 (6.94\%) women were diagnosed with AUB.

- A study reported the prevalence of $A U B$ is reported to be $20.48 \%{ }^{6}$

The second objective of the present study was to find out the contributing factors of AUB.

- The available sample was 273. About 93 (34.1\%) had maximum contributing factor with adenomyosis. Then, 50 (18.3\%) had iatrogenic as a contributing factor. There is no malignancy and hyperplasia and coagulopathy as a contributing factor.

- In a study, the most common cause of AUB found is leiomyoma (30\%), followed by adenomyosis (21\%) and ovulatory disorders (20\%), endometrial disorder (19\%), endometrial/cervical polyp $(8 \%)$, and not yet classified in $1 \%$ of the cases. ${ }^{6}$ 


\section{Conclusion}

The prevalence and contributing factors of AUB differ depending on the patient's age, parity, and reproductive status, according to the results of this report. According to the findings of this report, AUB can cause unnecessary disruption in women's daily activities, as well as serious medical consequences or exacerbation of anemia. The patient's morbidity can be minimized by a clear diagnosis that leads to the cause of AUB and timely care in the early stages. After PALM-COEIN has correctly identified AUB, patients may be treated medically or surgically depending on the cause, resulting in a higher cure and success rate.

\section{References}

1. Fraser IS, Critchley HO, Broder M, Munro MG. The FIGO recommendations on terminologies and definitions for normal and abnormal uterine bleeding. Semin Reprod Med 2011;29(5):383. DOI: 10.1055/s-0031-1287662.

2. Munro MG, Critchley HO, Fraser IS. The flexible FIGO classification concept for underlying causes of abnormal uterine bleeding. Semin Reprod Med 2011;29(05):391-399. DOI: 10.1055/s-0031-1287663.

3. Committee on Practice Bulletins-Gynecology. Practice bulletin no. 128: diagnosis of abnormal uterine bleeding in reproductive aged women. Obstet Gynecol 2012;120(1):197-206. DOI: 10.1097/ AOG.0b013e318262e320.

4. Whitaker L, Critchley HO. Abnormal uterine bleeding. Best Pract Res Clin Obstet Gynaecol 2016;34(54):65. DOI: 10.1016/j. bpobgyn.2015.11.012.

5. Deneris A. PALM-COEIN nomenclature for abnormal uterine bleeding. J Midwi Women's Health 2016;61(3):376-379. DOI: 10.1111/ jmwh.12440.

6. Choudhury SA, Nath P. Abnormal uterine bleeding; its prevalence, causes and management in a tertiary care hospital. New Indian Obgyn 2020;7(1):52-57. DOI: 10.21276/obgyn.2020.7.11. 